KATARZYNA BORZUCKA-SITKIEWICZ

ORCID 0000-0001-6079-3880

KARINA LEKSY

ORCID 0000-0001-5907-7836

Uniwersytet Śląki

w Katowicach

\title{
SOCIAL EXHIBITIONISM ON THE INTERNET AS A NEW RISKY BEHAVIOUR DEMONSTRATED BY POLISH YOUTH
}

\begin{abstract}
AвSTRACt. Borzucka-Sitkiewicz Katarzyna, Leksy Karina, Social Exhibitionism on the Internet as a New Risky Behaviour Demonstrated by Polish Youth [Społeczny ekshibicjonizm w Internecie jako nowe ryzykowne zachowanie polskiej młodzieży]. Studia Edukacyjne nr 57, 2020, Poznań 2020, pp. 89-101. Adam Mickiewicz University Press. ISSN 1233-6688. DOI: 10.14746/se.2020.57.7

The technological progress and unlimited access to media create new possibilities of self-presentation in the public domain nowadays, especially for the young generation. The article presents a part of a broader research project which was aimed at defining the characteristics of behaviors shown in cyberspace by Polish students of upper-secondary schools and also at determining potential social and health consequences of such behaviors. The chosen fragment of the study mainly focuses on those actions that were considered as a sign of social exhibitionism on the Internet, such as uploading photos and videos, sharing private information about oneself and informing about current activity. The research was conducted in accordance with a quantity paradigm. It was of diagnostic and verification nature and a method of diagnostic survey with the use of questionnaires was applied.
\end{abstract}

Key words: Internet, social media, social exhibitionism, risky behavior, youth

\section{Introduction}

Due to the technological progress and unlimited access to new media the possibility of auto-presentation in public space is gaining more and more significance. A special role here is played by the Internet, and in particular social 
networks, including the most popular one - Facebook. ${ }^{1}$ The social networks users are incredibly diversified, both in the context of motivational factors, which have become a stimulus to join the network or active (or not) participation in its functioning, as well as individual needs, which the membership in a certain network is to satisfy or types of behaviour or communication between the members. However, Suzana E. Flores ${ }^{2}$ notices that Facebook, first of all, "encouraged us to more often go out into the world" and made us "become a culture of public people", who like never before want to be visible to others, heard and observed. Consequently, a modern man lives on the one hand in a society of exhibitionism, and on the other hand - in the society of peeping. It turns out that it is common to use images and manipulate with your image in order to pass a certain piece of information to others. It would not be possible without the existence of an audience, which is ready to read the presented images, pay attention to other people's images and discover the meanings passed by such images. ${ }^{3}$ The commonly observed today social exhibitionism is mainly seen in a form of spreading in mass media (mostly on the Internet) a countless number of photos in a form of photo galleries (such as Flickr.com), photo blogs, social networks (Facebook, Instagram), as well as amateur video recordings or films (e.g. on YouTube). ${ }^{4}$ Moreover, the social networks also enable the use of features connected with location, such as check-in and mark location, which may also be treated as a manifestation of the social exhibitionism.

There is no doubt that the possibility of positive self-presentation, which is given by the cyberspace, creates new perspectives for self-promotion which is especially important to individuals with narcissistic tendencies. Simultaneously, it should be highlighted that teenage Facebook users show a stronger inclination for such tendencies. Social media, by giving a tool thanks to which their users are in the spotlight, encourage to focus on self-image as never before. ${ }^{5}$ Because of the above-mentioned reasons, Facebook has been simply accused of promoting narcissism since its users can ceaselessly show their idealized "self" by using for this purpose easily accessible means of self-pres-

${ }^{1}$ E. Lee, J. Ahn, Y.J. Kim, Personality traits and self-presentation at Facebook, Personality and Individual Differences, 2014, 69, p. 162-167.

2 S.E. Flores, Facehooked. How Facebook Affects Our Emotions, Relationships, and Lives, Reputation Books, Tiburon CA 2014, p. 34-35.

${ }^{3} \mathrm{~J}$. Choi, Y. Kim, The moderating effects of gender and number of friends on the relationship between self-presentation and brand-related word-of-mouth on Facebook, Personality and Individual Differences, 2014, 68, p. 1-5; G. Ranzini, E. Hoek, To you who (I think) are listening: Imaginary audience and impression management on Facebook, Computers in Human Behavior, 2017, 75, p. 228-235.

${ }^{4}$ A. Eftekhar, Ch. Fullwood, N. Morris, Capturing personality from Facebook photos and photo-related activities: How much exposure do you need? Computers in Human Behavior, 2014, 37, p. 162-170; L. Bareket-Bojmel, S. Moran, G. Shahar, Strategic self-presentation on Facebook: Personal motives and audience response to online behavior, Computers in Human Behavior, 2016, 55, p. 788-795.

${ }^{5}$ S.E. Flores, Facehooked. How Facebook, p. 146-147. 
entation. According to Soraya Mehdizadeh, ${ }^{6}$ there are two features of virtual reality that favour narcissistic tendencies. The first of them manifests itself in (typically) a considerable amount of positive comments made by friends (usually under users' photos) which affirm physical attractiveness of a person. The second concerns the possibility of presenting onself in the most desirable way thanks to the opportunity of self-presentation control which is given by the network. ${ }^{7}$ However, it should be emphasised that overediting of self-image may involve serious consequences for psychosocial functioning, such as low self-esteem, depression, and excessive focus on other people's opinion when making decisions and deciding who to be and what to think. ${ }^{8}$

Nowadays, being a member of a social network is for the young generation not only fashion, but also a natural element of everyday functioning. Adolescents are spending more and more time on networks where they create a more or less real image of themselves. Moreover, young Internet users eagerly share various information about themselves, they provide their age, address, interests and other private data. ${ }^{9}$ However, David Kirkpatrick ${ }^{10}$ notices that such actions may provoke negative situations, which the social network users would rather avoid. In addition, the amount of time which the Internet users spend on editing and correcting their image, decreased need for privacy which they display, and pressure to play certain roles for others by means of their profiles on social networking websites ${ }^{11}$ may be worrying.

\section{Methods}

The results presented in this article are a part of a broader research project which aims at defining the characteristics of behaviours shown in the cyberspace by Polish students of upper-secondary schools and also at determining potential social and health consequences of such behaviours. The presented fragment of the conducted research mainly focuses on those actions that were considered as a sign of social exhibitionism on the Internet, such as uploading photos and videos, sharing private information about oneself and informing about current activity.

${ }^{6}$ S. Mehdizadeh, Self-Presentation 2.0: Narcissism and Self-Esteem on Facebook, Cyberpsychology, Behavior, and Social Networking, 2010, 13, 4, p. 358.

7 G.G. Scott et al., Posting photos on Facebook: The impact of Narcissism, Social Anxiety, Loneliness, and Shyness, Personality and Individual Differences, 2017, http://dx.doi.org/10.1016/j. paid.2016.12.039

8 S.E. Flores, Facehooked. How Facebook, p. 56.

${ }_{9}$ Ibidem, p. 43-45.

${ }^{10}$ D. Kirkpatrick, The Facebook Effect: The Inside Story of The Company That Is Connecting The World, New York 2010, p. 202.

${ }^{11}$ S.E. Flores, Facehooked. How Facebook, p. 32-34. 
The research was conducted in accordance with a quantity paradigm which gives the opportunity of mass description and creation of objective knowledge which constitutes the basis for discovering laws and formulating regularities that concern phenomena under study. They were of diagnostic and verification nature which means that the research questions were in the form of questions about variables as well as about relationships between variables. ${ }^{12}$ A method of diagnostic survey with the use of questionnaires was used in the research. An independent survey questionnaire which consisted of 41 questions, including 28 half open questions, 4 rank order questions, 8 rating scale questions and 1 open question served for conducting the research. ${ }^{13}$ Before setting about the actual research, pilot study was conducted thanks to which essential modifications of the research tool were made - some formulations were clarified and slight changes in several multiple-choice answers were introduced. The obtained data was subjected to quantity and quality analysis. Statistica 12 programme was used in order to conduct the statistical analysis.

Selection of people for the research was of intentional character and the age of the respondents constituted selection criteria. The research sample was representative for the Silesia Province to which 390 students from two middle schools located in urbanistically diversified areas were qualified. 164 students attended school in a small town (up to 10,000 residents), 226 students attended school in a big city (over 100,000 residents). The respondents were in 13 to 16 age bracket, however, 14-year-olds and 15-year-olds constituted the most numerous groups (82 and 74 respondents respectively). Among the respondents, there were 198 girls, 186 boys, 6 respondents did not determine their sex.

More than $85 \%$ of the respondents used the Internet daily in various locations, but mostly they did it at home and school. On days off from school, the vast majority of the respondents spent on the Internet more than 3 hours daily, $40 \%$ of the respondents did so on school days. For surfing the Internet, they used various devices, not only computers and laptops, but first of all mobile phones, TV sets, video game consoles, iPads, etc.

\section{Results}

Positive self-presentation is an important aspect of online life, especially for the adolescents. Showing oneself on the Internet often involves sharing private photos, information about oneself (including personal data), information about where a person currently stays, current activity and short vid-

${ }^{12}$ G. Thomas, How to do your research project, London 2013, p. 110-123.

${ }^{13}$ Ibidem, p. 207-217. 
eos of himself/herself. In the case of the researched group, sharing photos was the most common way of self-presentation on the Internet. $76 \%$ of the respondents admitted to such form of self-promotion. About one-third of the surveyed admit that they inform the "online audience" about their current activity (30.6\%), $16.6 \%$ of the researched share short videos of themselves, while $10.7 \%$ of the surveyed share private information about themselves. Among other answers concerning what kind of information and materials the surveyed share on the Internet, most often there were: music, game videos and achievements, statuses and emoticons, comments and posts shared on social networking websites (primarily on Facebook). Moreover, it should emphasized that as many as 119 respondents did not give an answer in the issue under consideration.

While conducting the own research, efforts were made to determine which information and/or materials the examined young people would never share on the Internet because of potential risk to their health and safety. As a result of the performed analysis, it was stated that the respondents most frequently indicated their passwords to their Internet accounts (86\% of the surveyed), protection of detailed information about their family $(75.1 \%)$ and not sharing their residential address (72.1\%). Simultaneously, only $4.6 \%$ of the surveyed indicated that there was no such information which they could not share on the Internet. What seems to be interesting is the fact that among other answers $(1.3 \%)$ there were opinions that the surveyed would never share a "naked selfie" and "embarrassing photos".

The relationship between average time spent on the Internet and perception of sharing self-image and personal data were also subjected to analysis in terms of risk. For this purpose the Mann-Whitney $U$ test was used. An existence of a statistically important relationship between time spent on using the Internet (both on school days and days off) and a statement that sharing self-image and personal data on the Internet is safe $(p=0.020$ and $p=0.004$ respectively) was found. Similar relationship was shown in the case of the opinion that the potential risk is connected with whom personal photos and information are shared ( $p=0.006$ and $p=0.023$ respectively). It is also essential that people who spend a lot of time on the Internet do not see any risk in the possibility of spreading embarrassing contents about them and in the possibility that someone may impersonate them.

In order to determine the nature of cyber social relations of the respondents, they were asked whether they had an account on any social networking website. As discovered, the activity of the respondents in this field was very broad - almost all of them were a member of a social networking website, at the same time it is worth stressing that Facebook was the most popular (91.3\% of indications), Twitter and NK [Our classmates - one of the Polish 
social networking websites] were definitely less popular $(24.4 \%$ and $17.4 \%$ of indications respectively). Additionally, the surveyed had an option to indicate a social networking website that was not included in the cafeteria. This option was chosen by $33.1 \%$ of the respondents who mentioned surprisingly numerous websites which they used for potential cyber contacts, among them there were: Ask.fm (67 indications), Instagram (50 indications), Tumblr (19 indications), Snapchar (16 indications), Youtube (10 indications), Skype (8 indications), Blogger (4 indications), Gadu-Gadu (4 indications), Twitch (3 indications), and also some others that were individually indicated. Only $5.4 \%$ of the respondents indicated that they did not have an account on any social networking website. To sum up, it can be stated that social relations that are initiated or maintained online seem to be very important to the surveyed. Simultaneously, in the context of the issue under discussion, it should be noticed that although there are many websites that are created by and for teenagers and which have various functions (blogs, social networking websites), still the majority of them focus on sharing photos and audio and video recordings since they are the basic and obligatory means of expression. ${ }^{14}$

The great power of social networking websites, and particularly Facebook, lies in the possibility of exchanging information without the necessity of physical contact. Consequently, it provides simply unlimited expression and interpersonal relations. What is more, sharing information on social networking websites is no longer only a link between an individual and the rest of the world, but for many it has also become an alternative reality where profiles are treated "dead seriously". ${ }^{15}$ Bearing in mind the aforementioned statement, in order to specify more precisely the significance of online social contacts, the respondents were asked how important it was for them to be a member of social networking websites. The answers prove that online activity on such social networking websites is extremely important to the majority $-34.1 \%$ declare that at least once a day they log in to their accounts in order to be up to date with shared information, $21 \%$ underline that they care about interaction with other registered users, and the next $20.6 \%$ say that they log in to their accounts several times a day and that they cannot imagine their life without constant participation in online community. Only $5.9 \%$ of the respondents declare that they are not a member of any social networking website and that such activity is not important to them.

As Suzana E. Flores notices, ${ }^{16}$ every decision made by Facebook users (such as: where to go, who to meet, or what to wear) is based on how they will be perceived on the Internet. That is why self-presentation is so important

\footnotetext{
${ }^{14}$ S.E. Flores, Facehooked. How Facebook, p. 144.

${ }^{15}$ Ibidem, p. 24, 41.

${ }^{16}$ Ibidem, p. 217.
} 
in the cyberspace, all the more that "the majority seem to treat Facebook as a display case for their own achievements and trophies which can be seen and admired by the others" ${ }^{\prime 17}$. In the own research efforts were also made to obtain an information whether the respondents present themselves only in a favourable light by sharing only attractive photos or information about achieved successes. The analysis of the obtained results shows that more than one-third of the surveyed (35.2\%) try above all to be themselves in both the "real" and virtual world. Almost an identical number of the surveyed (32.1\%) states that presenting themselves only in a favourable light on the Internet is unimportant to them. At the same time, only $11.1 \%$ admit that they always try to present themselves from an attractive side. What is also interesting is the way in which the surveyed care about their online image so that they are perceived as attractive. In times when the Internet and image editing programmes that serve for keeping up appearances are omnipresent, it is so easy to transform without any difficulty into somebody else - the more perfect and more attractive. ${ }^{18}$ As a result of the performed analysis, it turns out that for $67.5 \%$ of the respondents their image on the Internet is not important. In turn, $28.3 \%$ of the respondents admit that for this purpose they share only attractive photos on the Internet.

As a consequence of daily social interactions, the way how the adolescents think about themselves may be subject to constant transformations. Today it can be even said that young people are addicted to feedback which they receive via their computers, smartphones, and social networking websites. Such information influences significantly the way how teenagers perceive themselves, each other, and the world around them. ${ }^{19}$ Therefore, while conducting own research, efforts were made to evaluate the significance of messages and feedback that are received in the cyberspace. As a result of the performed analysis, it can be stated that the respondents first of all pay their attention to positive messages, such as: positive comments ( $\mathrm{av}$. $=3.32 ; \mathrm{M}=4.00)$, being tagged by other users of social networking websites (av. = 2.97; $\mathrm{M}=3.00$ ), and "likes" (av. =2.86; $\mathrm{M}=3.00$ ), whereas they ignore pejorative messages in the form of taunts (av. $=2.41 ; \mathrm{M}=2.00$ ) and negative comments (av. = 2.33; $M=2.00$ ). However, it can be assumed that in this way they try to show that such messages do not have any emotional significance to them. In this context, opinions included in the category "others" seem to be interesting - they suggest that the respondents especially care for those messages which prove

17 Ibidem, p. 62; Y-CH.J. Wu, W.-H. Chang, Ch-H. Yuan, Do Facebook profile pictures reflect user's personality? Computers in Human Behavior, 2015, 51, p. 880-889.

18 A. Błachnio et al., Self-presentation styles, privacy, and loneliness as predictors of Facebook use in young people, Personality and Individual Differences, 2016, 94, p. 26-31.

19 S.E. Flores, Facehooked. How Facebook, p. 140. 
being accepted by peers ("messages, invitations", "chatting with many people") or provide information which is significant from the social point of view ("where and with who somebody hangs out").

There is no doubt that the option of "liking" posts is one of the most important functions on Facebook. For its users, it constitutes an absolutely essential tool since it often sets the way of acting and thinking about oneself. Moreover, receiving "likes" has also a deeper significance - it means that users' friends accept and praise their appearance, visited places, opinions expressed publicly, or their decisions. ${ }^{20}$ Bearing in mind the aforementioned opinion, the respondents were asked, as a part of the own research, what a large amount of "likes" means to them. It was found that the respondents most frequently chose the answers that indicated confirmation of a status and/or social acceptance, such as: popularity among peers (av. $=3.71$; $\mathrm{M}=4.00$ ) and being liked by others (av. =3.59; $\mathrm{M}=4.00$ ). According to the surveyed, "likes" prove physical attractiveness in the slightest degree, however, this answer was also highly scored (av. =3.12; $\mathrm{M}=3.00$ ). Additionally, in the option "other", the surveyed mentioned such meanings of "likes" which could be related to social aspects of their functioning ("popularity among older friends", "I am friendly") and expectations of reciprocation which was assessed by them positively ("[they express] hope that a person whom we give a "like" will repay in the same way", "one can ask others for "likes" and receive a lot of them", "joining groups where users give likes to each other"), as well as negatively ("[they prove] swankiness and insincerity", "[they prove] moronity"). Summing up, it can be stated that a lot of contemporary teenagers assess their popularity through the amount of received "likes" on Facebook. Moreover, for many teenagers "lack of followers on Twitter or lack of 'likes' on Facebook are equivalent to rejection". ${ }^{21}$ This thesis is also confirmed by the conducted research. When asked what lies behind small amount of Facebook likes, the respondents indicated above all social consequences, such as: little popularity (av. =3.08; $\mathrm{M}=3.00)$, small amount of friends (av. $=2.97 ; \mathrm{M}=3.00)$, and not being very liked by others (av. = 2.94; $\mathrm{M}=3.00$ ). In the context under analysis, it should be added that likes and positive comments on Facebook are of such great importance to teenagers that they try to get as many of them as possible no matter who gives them..$^{22}$ The number of followers or fans (e.g. on Twitter or Instagram)

${ }^{20}$ Ibidem, p. 230; R.J. Lee-Won et al., Who puts the best "face" on Facebook?: Positive self-presentation in online social networking and the role of self-consciousness, actual-to-total Friends ratio, and culture, Computers in Human Behavior, 2014, 39, p. 413-423.

${ }^{21}$ S.E. Flores, Facehooked. How Facebook, p. 151.

22 A. Lenhart et al., Social Media and Mobile Internet Use Among Teens and Young Adults, 2010 file:///D:/Download/PIP_Social_Media_and_Young_Adults_Report_Final_with_toplines.pdf 
is also important - the bigger the number, the more teenagers believe that they are interesting for others. The approval received on the Internet can doubtlessly lead to an increased sense of self-esteem. However, if young users realise that they are not so interesting outside the Internet world, it can lead to uncertainty about their identity, anxiety, and a feeling of being lost. ${ }^{23}$

\section{Discussion}

Creating self-image (that is manipulating the image of oneself) is contemporarily a very popular practice and is visible in manifesting one's character, attitudes, opinions, or views, usually in their best form. ${ }^{24}$ It happens because attractive image is one of the most essential criteria of social position in the contemporary world. According to Junghyun Kim and Jong-Eun Roselyn Lee, ${ }^{25}$ there are two strategies of self-presentation on Facebook: the first of them is "exposing oneself without any limits", the second consists in idealisation of self-image which leads to ceaseless presentation of features that will gain approval of the cyber community. Developing one's cyber identity consists mainly in sharing appropriately selected photos and personal information and in selecting preferred groups of friends on social networking websites. As a consequence, many users of social networking websites assume completely new identities using for this purpose some technical possibilities of creating, overrating, and editing themselves. ${ }^{26}$ It is worth emphasising that self-presentation in social media has become a structural norm and social practice which are an extremely important factor that regulates interpersonal relationships, especially in the circle of the young generation. What is more, being present and visible in social media is becoming simply a necessity, not a choice. Sharing their everyday life mainly by means of photos has already become an norm among the young. ${ }^{27}$

As the conducted research shows, for more than one-fourth of the respondents satisfying the need for being noticed and appreciated is one of the principal reasons for establishing online social interactions. There is no doubt

\footnotetext{
${ }^{23}$ S.E. Flores, Facehooked. How Facebook, p. 147.

${ }^{24}$ G. Seidman, Self-presentation and belonging on Facebook: How personality influences social media use and motivations, Personality and Individual Differences, 2013, 54, p. 402-407.

${ }^{25}$ J. Kim, J.E.R. Lee, The Facebook Paths to Happiness: Effects of the Number of Facebook Friends and Self-Presentation on Subjective Well-Being, Cyberpsychology, Behavior, and Social Networking, 2011, 14, 6, p. 359-360.

${ }^{26}$ S.E. Flores, Facehooked. How Facebook, p. 44.

27 A. Hetsroni, D.A. Guldin, Revealing Images as Facebook Profile Pictures: Influences of Demographics and Relationships Status, Social Behavior and Personality, 2017, 45(6), p. 987-998; S. Mehdizadeh, Self-Presentation 2.0: Narcissism.
} 
that having a wide circle of "friends" in the cyberspace gives young people a sense of satisfaction and increases their self-esteem. Consequently, as the research conducted by EU Kids Online show ${ }^{28}-44 \%$ of girls and $39 \%$ of boys between 9 and 16 look for friends on the Internet, and 31\% of girls and 28\% of boys add Internet strangers to their friends list or to their mailing list. Such behaviours, which are considered as risky behaviours, may expose teenagers to danger in both online and offline reality.

On the basis of the conducted research, it may seem that when young users of the Internet share their photos and information about themselves, they try to be authentic which means they try to be just as they really are and that they are not particularly concerned about distorting (improving, making better) their image on the Internet. On the other side, it is worth considering whether such declarations are perfectly honest. If we examine closely e.g. photos of the students of middle school (especially female students) that they share on social networking websites (Facebook, Instagram in particular), it is difficult not to get the impression that these photos are carefully selected, they depict a person in definite poses and in fashionable clothes in order to win social approval and popularity among peers - it is proved by large amount of "likes" and comments full of adoration whose significance was emphasised by the respondents in the conducted research. It can also be assumed that by sharing their (rather more attractive) image on the Internet and receiving positive feedback (no matter if it is honest or not), people start to believe in it and become convinced that they have all those positive features and that they really are as they present themselves on the Internet. ${ }^{29}$ Such interpretation of the results of the own research could be confirmed by, among others, conclusions reached by Amy L. Gonzales and Jeffrey T. Hancock. ${ }^{30}$ According to them, as a result of selective self-presentation and positive feedback received from other users, Facebook users can at the same time increase their sense of self-esteem and establish relationships more easily (also in "face to face" situations). However, it is worth knowing that many users filter the content and share only "proofs for their glory moments" avoiding in this way presenting their true self. ${ }^{31}$ It turns out that many users of social networking websites share only positive aspects of their life hiding at the same time everything that they consider as negative. ${ }^{32}$

${ }^{28}$ S. Livingstone et al., In their own words: what bothers children online? European Journal of Communication, 2014, 29(3), p. 271-288.

${ }^{29}$ J. Kim, J.E.R. Lee, The Facebook Paths to Happiness, p. 359-360.

30 A.L. Gonzales, J.T. Hancock, Mirror, Mirror on my Facebook Wall: Effects of Exposure to Facebook on Self-Esteem, Cyberpsychology, Behavior, and Social Networking, 2011, 14, 1-2.

${ }^{31}$ S.E. Flores, Facehooked. How Facebook, p. 25.

${ }^{32}$ Ibidem, p. 49. 
When it comes to self-presentation on the Internet, making one's sense of self esteem subject to approval of the cyber community constitutes a great problem and as a result it may not only be addictive, but also harmful for psychosocial functioning of an individual. As S.E. Flores notices, ${ }^{33}$ when identities that were created for a social networking website are not reflected in what a person represents in direct contact or are contrary to each other, then the phenomenon of cognitive dissonance emerges. It means anxiety which is felt as a result of two contradictory ways of perceiving the world. An individual will not avoid identity conflicts, feeling of being lost, and - in extreme cases psychotic episodes. Moreover, attaching too much significance to what other people think, searching for confirmation of self-esteem and subjecting it to approval of the cyber community are perhaps exhausting, but they may also indicate that a person does not accept himself/herself. ${ }^{34}$ Being addicted to Internet approval causes that a person ceases to trust himself/herself and to believe in his/her abilities and strengths and starts to focus his/her attention only on feeding the lack of self-confidence and starts to live his/her "Facebook life" only.

The discussed phenomena cause that in contemporary reality adults meet a new challenge and that is the necessity to prepare young people for smart and safe use of new media. Shaping skills in using modern information and communication technologies is an important objective of contemporary education since young Internet users are not aware of its dangers and are not always able to handle risk situations. This is an indication to the need for taking actions that aim at increasing children's and young people's competencies in this field that will cover developing skills of safe use of new technologies.

In the context under analysis, it seems essential to organise cyclical advisory class which would shape skills in creating self-image on the Internet and provide complex information about multi-dimensional dangers and risks for health, mental, and social functioning that occur on the Internet. It is worth maintaining balance in perceiving oneself and that is balance between the former "analogue self" and new cyber relationships. ${ }^{35}$ In the real world, praise and attention on social networking websites has little in common with a man's real worth. Therefore, it is worth taking care so that especially young people instead of trying to "earn" their self-esteem through receiving likes for their posts or decisions learn how to accept themselves. ${ }^{36}$

In addition, it is important, preferably by shaping appropriate behaviours, to show sensible ways of spending free time so that using computer is not the

\footnotetext{
${ }^{33}$ Ibidem, p. 43.

${ }^{34}$ Ibidem, p. 237-239.

35 Ibidem, p. 43.

${ }^{36}$ Ibidem, p. 242.
} 
sole available and attractive option. It is crucial to find balance between time spent online and offline and above all, to change priorities in organising time free from work or learning. ${ }^{37}$ It is also worth realising that the Internet and particularly Facebook are "the biggest time wasters". ${ }^{88}$ Moreover, it is necessary to shape social skills of contemporary teenagers so that they can establish interpersonal "face to face" relationships and do not have to resort to make social contacts in the cyberspace and build their self-esteem on that basis because of lack of those skills.

\section{BIBLIOGRAPHY}

Bareket-Bojmel L., Moran S., Shahar G., Strategic self-presentation on Facebook: Personal motives and audience response to online behavior, Computers in Human Behavior, 2016, 55.

Błachnio A., Przepiorka A., Boruch W., Bałakier E., Self-presentation styles, privacy, and loneliness as predictors of Facebook use in young people, Personality and Individual Differences, 2016, 94.

Choi J., Kim Y., The moderating effects of gender and number of friends on the relationship between self-presentation and brand-related word-of-mouth on Facebook, Personality and Individual Differences, 2014, 68.

Eftekhar A., Fullwood Ch., Morris N., Capturing personality from Facebook photos and photo-related activities: How much exposure do you need? Computers in Human Behavior, $2014,37$.

Flores S.E., Facehooked. How Facebook Affects Our Emotions, Relationships, and Lives, Reputation Books, Tiburon CA 2014.

Gonzales A.L., Hancock J.T., Mirror, Mirror on my Facebook Wall: Effects of Exposure to Facebook on Self-Esteem, Cyberpsychology, Behavior, and Social Networking, 2011, 14, 1-2.

Hetsroni A., Guldin D.A., Revealing Images as Facebook Profile Pictures: Influences of Demographics and Relationships Status, Social Behavior and Personality, 2017, 45(6).

Kim J., Lee J.E.R., The Facebook Paths to Happiness: Effects of the Number of Facebook Friends and Self-Presentation on Subjective Well-Being, Cyberpsychology, Behavior, and Social Networking, 2011, 14, 6.

Kirkpatrick D., The Facebook Effect: The Inside Story of The Company That Is Connecting The World, Simon \& Schuster, New York 2010.

Lee E., Ahn J., Kim Y.J., Personality traits and self-presentation at Facebook, Personality and Individual Differences, 2014, 69.

Lee-Won R.J., Shim M., Joo Y.K., Park S.G., Who puts the best "face" on Facebook?: Positive self-presentation in online social networking and the role of self-consciousness, actual-to-total Friends ratio, and culture, Computers in Human Behavior, 2014, 39.

Lenhart A., Purcell K., Smith A., Zickhur K., Social Media and Mobile Internet Use Among Teens and Young Adults, 2010 file:///D:/Download/PIP_Social_Media_and_Young_ Adults_Report_Final_with_toplines.pdf

Livingstone S., Kirwall L., Ponte C., Staksrud E., In their own words: what bothers children online? European Journal of Communication, 2014, 29(3).

\footnotetext{
${ }^{37}$ Ibidem, p. 257.

${ }^{38}$ Ibidem, p. 25.
} 
Mehdizadeh S., Self-Presentation 2.0: Narcissism and Self-Esteem on Facebook, Cyberpsychology, Behavior, and Social Networking, 2010, 13, 4.

Ranzini G., Hoek E., To you who (I think) are listening: Imaginary audience and impression management on Facebook, Computers in Human Behavior, 2017, 75.

Scott G.G., Boyle E.A., Czerniawska K., Courtney A., Posting photos on Facebook: The impact of Narcissism, Social Anxiety, Loneliness, and Shyness, Personality and Individual Differences, 2017, http://dx.doi.org/10.1016/j.paid.2016.12.039

Seidman G., Self-presentation and belonging on Facebook: How personality influences social media use and motivations, Personality and Individual Differences, 2013, 54.

Thomas G., How to do your research project, Sage, London 2013.

Wu Y-Ch.J., Chang W-H., Yuan Ch-H., Do Facebook profile pictures reflect user's personality? Computers in Human Behavior, 2015, 51. 